\title{
Geração de microcampos de deterioração psico-socioambiental proveniente da deposição irregular de lixo em áreas residenciais
}

O presente estudo teve como objetivo verificar a influência dos resíduos depositados em vazadouros a céu aberto em áreas urbanas, verificando os impactos causados pela proliferação de vetores em residências e doenças em membros das famílias do entorno destes focos, na cidade de Fazenda Rio Grande/PR, Brasil. A escolha dos lotes deu-se a partir da visita in loco a todas ruas e bairros da cidade, observando-se a presença de deposição massiva de resíduos domésticos nestes locais, como um dos critérios de escolha. Além disso, os lotes deveriam estar circunscritos à área urbana, a uma distância mínima de 100 metros de áreas marginais, áreas florestadas, alagadas e margens de rios. Utilizou-se questionário estruturado e entrevistaram-se os residentes do entorno destes terrenos. Para análise dos dados, utilizou-se o teste de correlação de postos de Spearman, que mede a associação entre duas variáveis no mínimo ordinais. Este teste é não paramétrico e não exige suposições sobre a distribuição dos dados. A medida chamada 'rho' é um valor que varia de -1 até 1, em que 1 indica correlação perfeita positiva (se a ordem de uma variável cresce, a outra tende a crescer também) e -1 indica correlação perfeita negativa, se a ordem de uma variável cresce, a outra tende a decrescer). Obteve-se uma correlação positiva para presença e frequência de ocorrência de vetores: moscas, baratas, ratos, animais de rua e para odores desagradáveis. Quanto às doenças, os resultados foram significativos para: infecções, diarreias, inflamações, problemas respiratórios, ansiedade e depressão. Tomando como pressupostos estes fatos e aportes teóricos da psicologia ambiental e geografia, propõe-se que os locais com as características descritas formam os microcampos de deterioração psico-socioambiental.

Palavras-chave: Vazadouros a céu aberto; Cidades; Resíduos sólidos; Socioambiental.

\section{Generation of psycho-socio-environmental deterioration microfields from irregular waste deposition in residential areas}

\begin{abstract}
The present study aimed to verify the influence of waste deposited in open air pit dumps in urban areas, verifying the impacts caused by the proliferation of vectors in homes and diseases on the family members around these outbreaks, in the city of Fazenda Rio Grande/PR, Brazil. The choice of lots took place from the on-site (in loco) visit, to all streets and neighborhoods in the city and observed the presence of massive deposition of domestic waste in these places, as one of the criteria of choice. In addition, the lots should be limited to the urban area, at a minimum distance of 100 meters from sea areas, forested areas, wetlands and river banks. A structured questionnaire was used and the residents around these lands were interviewed. For data analysis, Spearman's rank correlation test was used, which measures the association between two variables at least ordinal. This test is non-parametric and does not require assumptions about the distribution of the data. The measure called 'rho' is a value ranging from -1 to 1 , where 1 indicates perfect positive correlation (if the order of one variable grows, the other tends to grow too) and -1 indicates perfect negative correlation, if the order one variable grows, the other tends to decrease). A positive correlation was obtained for the presence and frequency of the occurrence of vectors: flies, cockroaches, rats, street animals and for unpleasant odors. As for diseases, the results were significant for: infections, diarrhea, inflammation, breathing problems, anxiety and depression. Taking as a premise these facts and theoretical contributions from environmental psychology and geography, it is proposed that the places with the described characteristics, form the microfields of psycho-socio-environmental deterioration.
\end{abstract}

Keywords: Open air dumps; Cities; Solid waste; Socio-environmental.

Topic: Desenvolvimento, Sustentabilidade e Meio Ambiente

Reviewed anonymously in the process of blind peer.
Received: $17 / 03 / 2020$

Approved: 19/04/2020

João Batista Alves (iD

Universidade Federal de Campina Grande, Brasil

http://lattes.cnpq.br/2775708005526266

http://orcid.org/0000-0002-1548-7996

alvesjb@uol.com.br

d

DOI: 10.6008/CBPC2179-6858.2020.003.0027
Referencing this:

ALVES, J. B.. Geração de microcampos de deterioração psicosocioambiental proveniente da deposição irregular de lixo em áreas residenciais. Revista Ibero Americana de Ciências Ambientais, v.11, n.3, p.349-366, 2020. DOI: http://doi.org/10.6008/CBPC2179$\underline{6858.2020 .003 .0027}$ 


\section{INTRODUÇÃO}

Os resíduos sólidos são presença marcante na sociedade humana e resultam dos seus processos produtivos. Nas sociedades antigas, eram biodegradáveis e, nas pós-modernas, o avanço técnico-científico propiciou a criação de elementos sintéticos, os quais, em grande parte, não se degradam naturalmente, portanto, potencialmente, podem causar danos ao meio ambiente, à saúde individual e pública (DORST, 1973; FIGUEIREDO, 1994; WALDMAN, 2010).

Um impacto relevante relacionado aos resíduos sólidos refere-se ao processo de deposição, notadamente os dispostos clandestinamente nos espaços urbanos e rurais, conhecidos por vazadouros a céu aberto. Em áreas urbanas, são depositados em terrenos baldios, calçadas e ruas, trazendo transtornos à vizinhança e à área urbana como um todo. Associada a esse aspecto emerge uma intricada 'teia' de relações entre conteúdos socioambientais do espaço ocupado, devido à dinâmica que se instala entre esses resíduos e a população, podendo causar inúmeros impactos socioambientais e submetendo a população a riscos e vulnerabilidades.

Diante do exposto, este trabalho se propõe a investigar a influência dos resíduos depositados em vazadouros a céu aberto, incluindo a proliferação de vetores e doenças, em membros das famílias residentes no entorno destes focos e suas consequências, na área urbana da Fazenda Rio Grande/PR, Região Metropolitana de Curitiba - RMC.

\section{METODOLOGIA}

\section{Problemas socioambientais causados pelos resíduos sólidos}

A literatura referente à questão dos resíduos sólidos é bastante ampla. Diversos estudos têm sido realizados ao redor do mundo, em especial, aqueles relacionados à questão da geração, gravimetria, tratamento e disposição final. Em menor escala, há os trabalhos que tratam dos efeitos sobre a saúde humana de quem lida com os resíduos, sobre o ambiente e a sociedade em geral. Nesse sentido, podem-se citar alguns autores que tratam da questão dos riscos socioambientais provenientes da deposição e tratamento dos resíduos, como: Dorst (1973); Figueiredo (1994); Rodrigues (1998); Lima (2001); Veloso (2008); Waldman (2010) e Santos et al. (2012), entre outros.

Nesse contexto, Veyret (2007) menciona o risco como "objeto social" e conceitua-o "como a percepção do perigo e da catástrofe possível". Tem existência apenas em relação a um indivíduo ou grupo social ou profissional, "uma comunidade, uma sociedade que apreende por meio de representações mentais e com ele convive por meio de práticas específicas [...] correm-se riscos, que são assumidos, recusados, estimados, avaliados, calculados".

Entende-se que, associados a resíduos, estão os impactos ambientais provocados pela artificialização cada vez mais intensa dos produtos. Com esta prática, injetam-se na natureza as mais diversas substâncias químicas que não podem por ela ser processadas ou levam intenso período de tempo para degradação, sem ao menos saber se serão realmente incorporadas pelo meio natural, pois são de outra natureza, como 
plásticos, produtos químicos e radioativos. Da mesma forma, é importante destacar que as retiradas de substâncias, que estão dispersas na natureza em baixas concentrações, são captadas, concentradas, integradas a produtos e depois descartadas, inclusive em locais distantes da sua origem. Dentre essas substâncias, destacam-se alguns minerais e, dentre eles, os metais pesados, como cobre, mercúrio e chumbo, que se acumulam nas cadeias produtivas e são absorvidos por plantas e animais. Nos seres humanos, podem causar distúrbios físicos e mentais.

Especificamente quanto à questão dos problemas de saúde física e mental gerados pelos resíduos, os estudos concentram-se naqueles ligados às pessoas que trabalham diretamente como os mesmos. Contudo, novos estudos vêm sendo desenvolvidos para detectar a influência dos depósitos de lixo tóxico, aterros sanitários e incineradores, sobre a saúde de populações do entorno, bem como os problemas psicofísicos causados notadamente pelos resíduos de produtos industrializados. Dentre esses trabalhos, pode-se citar: Secretaria Especial de Desenvolvimento Urbano da Presidência da República - SEDU (2001); Lima (2001); Ferreira et al. (2001); Nunesmaia (2002); Orsi (2002); Heller (2002); Muñoz (2002); United Nations Environment Programme - UNEP (2006); Moraes (2007); Nakayama et al. (2006); Thompson et al. (2008) e Makhubele et al. (2019)

Os autores citados relatam doenças relacionadas aos resíduos quando a população entra em contato, aproxima-se ou reside próximo aos locais de tratamento e deposição. Em especial, há destaque para as doenças infecto- contagiosas provenientes de vetores presentes nestes ambientes, tais como ratos, moscas, baratas. Registram-se também referências aos contaminantes ambientais, advindos principalmente da presença de metais pesados e gases poluentes, dentre eles, dioxinas e os furanos. Outro aspecto que chama a atenção, mas que ainda requer mais pesquisas, relaciona-se à influência dos locais de tratamento e deposição de resíduos nas doenças em esfera psicológica, como a ansiedade e a depressão.

Nakayama et al. (2006) abordaram efeitos negativos na saúde mental dos trabalhadores de incineradores; Thompson et al. (2008) relatam problemas de saúde fisiológicos, comportamentais e psicológicos, entre eles, a doença da depressão em pessoas que vivem nas proximidades de incineradores de resíduos. Na mesma seara, Geschwind et al. (1992) citam os problemas de saúde causados em fetos de mães que moram próximo a depósitos de lixo perigosos. Na mesma seara, Crowley et al. (2003) mencionam os diversos problemas de saúde associados a aterros sanitários, devido à liberação de gases, entre eles, o metano e o dióxido de carbono. Contudo, esses autores ressaltam que os resultados destas pesquisas não foram considerados suficientes para relacionar tais empreendimentos às doenças psíquicas, pois havia provas antagônicas entre os diversos trabalhos.

Por outro lado, um exemplo de correlação positiva foi detectado na pesquisa de Muñoz (2002) sobre os impactos socioambientais causados pelo Aterro Sanitário e Incinerador no município de Ribeirão Preto $\mathrm{SP}$, em que o mesmo identificou a presença de maiores concentrações de cádmio, cromo, chumbo, manganês, zinco, cobre e mercúrio no solo, na água e no chorume no entorno destas instalações e inferindo possíveis danos à saúde pública decorrentes destas atividades. 
Os minerais supracitados, bem como outros, são partes constituintes de resíduos de produtos eletrônicos, atualmente produzidos em larga escala. Segundo a SEDU (2001), "há um potencial poluidor neste tipo de resíduos", e os males causados às pessoas contaminadas são os mais diversos, tais como: dores abdominais; disfunção renal; anemia; problemas pulmonares; neurite periférica (paralisia); encefalopatia; gengivite; salivação excessiva; diarreias; congestões; inapetência; indigestão, estomatites; dermatites; elevação da pressão arterial; ulceração da faringe e do esôfago; insônia; dores de cabeça; colapsos; delírios; convulsões; lesões cerebrais e neurológicas, que provocam desordens psicológicas; disfunções do sistema neurológico; câncer; entre outras.

Triassi et al. (2015), que realizaram uma revisão sobre os estudos realizados, até aquela data, sobre a deposição de resíduos em áreas abertas, de forma ilegal, na região de Campania, Itália e efeitos na saúde da população da região, alertaram para alguns problemas de estudos dessa natureza, que apresentam resultados contraditórios e, às vezes, não conclusivos. Segundo os autores, primeiro, há a inadequação das informações, tais como a heterogeneidade metodológica e amostral; segundo, usam dados padronizados e estatísticas atrasadas de instituições; terceiro, há problemas da localização exata onde estão os depósitos ilegais e, quarto, o biomonitoramento em humanos começou apenas recentemente devido à dificuldade de encontrar colaboradores.

Há, também, a questão do levantamento dos níveis de exposição da população aos resíduos; a identificação da localização das populações em risco; a que tipo de produtos estão expostos (produtos químicos e substâncias tóxicas) e as condições socioeconômicas dos residentes (educação, desemprego, propriedade da moradia, condições da habitação e estrutura familiar). Todos estes são fatores que podem interferir nas condições de saúde e que levam os estudos realizados a não trazerem resultados conclusivos (TRIASSI et al., 2015). Mesmo assim, os autores fazem alusão de que é possível a correlação entre a exposição a longo prazo aos resíduos e mortalidade por alguns tipos de câncer, bem como malformação congênita, e mencionam, ainda, que há significativos desastres socioambientais resultantes da deposição e contaminação pelos resíduos. Em suma, a problemática dos resíduos sólidos coloca em risco grande parte da humanidade direta ou indiretamente exposta aos mesmos.

Mesmo considerando os problemas relacionados diretamente à questão dos resíduos e problemas de saúde, não se pode esquecer que estes resíduos estão sendo dispostos em algum local no espaço. Nesse sentido, é preciso levar em consideração o que menciona Rodrigues (1998), quando destaca que, no findar do século $\mathrm{XX}$, o processo de destruição da natureza foi acelerado, o que deve ser compreendido como produto da contradição do modo de produção industrial tanto capitalista quanto o socialista. Estas contradições manifestam-se no espaço, produzindo "ao mesmo tempo mercadorias e territórios desejáveis e vendáveis e mercadorias e territórios indesejáveis". Aqueles são parte integrante do ideário e fazem parte dos ideais de desenvolvimento e dos símbolos de todas as pessoas. Segundo a autora, o termo "indesejável" é usado porque não foram planejados como mercadorias. Assim, os produtos produzidos para o desenvolvimento geram problemas, os quais demonstram a contradição do modelo de produção, e esta é 
"uma das raízes da descoberta da problemática ambiental para uma (re) descoberta e uma (re) definição da metáfora espacial" (RODRIGUES, 1998). Esta foi uma das causas do surgimento dos movimentos ambientalistas e que gerou a crise política da razão.

Outra questão relacionada ao espaço e seu uso é a confusão que o cidadão comum, no Brasil, faz entre a esfera pública e privada. Damatta (1997) menciona: em casa somos "supercidadãos" e na rua passamos por "indivíduos anônimos e desgarrados", quase sempre "maltratados pelas autoridades", não tendo nem paz nem voz. Cita ainda que

\begin{abstract}
Somos rigorosamente "subcidadãos" e não será exagerado observar que, por causa disso, nosso comportamento na rua (e nas coisas públicas que ela necessariamente encerra) é igualmente negativo. Jogamos o lixo para fora de nossa calçada, portas e janelas; não obedecemos às regras de trânsito, somos até mesmo capazes de depredar a coisa comum, utilizando aquele célebre e não analisado argumento segundo o qual tudo que fica fora de nossa casa é um "problema do governo"! Na rua a vergonha da desordem não é mais nossa, mas do estado. Limpamos ritualmente a casa e sujamos a rua sem cerimônia ou pejo [...]. Não somos efetivamente capazes de projetar a casa na rua de modo sistemático e coerente, a não ser quando recriamos no espaço público o mesmo ambiente caseiro e familiar. (DAMATTA, 1997).
\end{abstract}

No debate em relação ao público, o privado, uso do espaço e a questão dos resíduos sólidos, Rodrigues (1988) enfatiza que a problemática do lixo na contemporaneidade está criando novos territórios indesejáveis ou segregados, ou seja, as áreas onde são dispostos os mais diversos tipos de resíduos.

Nessa discussão em relação ao público, o privado, uso do espaço e a questão dos resíduos sólidos, os espações indesejáveis a que se refere Rodrigues (1988) fazem parte do que a autora denominou de "intercâmbio ecologicamente desigual", que ocorre entre regiões, países, podendo ocorrer até mesmo numa cidade, "como é o caso dos depósitos de lixo doméstico, que devem ser situados cada vez mais longe, e que têm servido para a sobrevivência dos mais pobres que coletam os restos". Para a autora, a partir do sistema de informações vigente, remete-se a culpa pela poluição somente aos mais pobres.

Ainda segundo essa autora, verifica-se que a questão ambiental requer uma releitura do território, e a questão que persiste é: "como realizar releituras do território que não camuflem, ocultem as relações sociais e as formas como se dão a apropriação da natureza e de sua exploração é um enorme desafio". Para se construir uma sociedade sustentável, é necessário enfrentar este desafio (RODRIGUES, 1998).

Dentre esses espaços indesejáveis abordados por Rodrigues (1998), estão os aterros sanitários, os lixões, depósitos de lixo tóxico, etc. Podem-se somar a estes os resíduos dispostos a céu aberto, ou seja, em espaços livres, em especial, nos países menos desenvolvidos e em desenvolvimento. A esse respeito, uma ampla literatura trata dessa questão, tanto no Brasil com em outros países, como, por exemplo: Figueiredo (1994) e Waldman (2010), no Brasil; Joseph (2002), Índia; Reyes (2004), Cidade do México; UNEP (2006), várias cidades ao redor do mundo; Bandara (2010), Sri Lanka; Jalil (2010), Malásia; Fazzo et al. (2011), Itália; Mudzengerere et al. (2012), Zimbabwe; Cavallet et al. (2013); Oliveira et al. (2016); Toro et al. (2016); Wolff et al. (2016); Fazzo et al. (2017) e Brandão Junior et al. (2018).

Esses dois últimos trabalhos citados são estudos revisionais, sendo o penúltimo abrangendo a região europeia, que trata do impacto da exposição da população residente próximo a locais de deposição de 
resíduos industriais. Aqueles autores relatam evidências de problemas de saúde em ambientes que sofreram deposição de agentes químicos derivados do petróleo. Já o último abrange Literatura Latino-Americana e do Caribe em Ciências da Saúde (LILACS), Índice Bibliográfico Espanhol em Ciências da Saúde (IBECS) e Medical Literature Analysis and Retrieval System Online (MEDLINE).

Diante do exposto, pode-se inferir que viver ou estar em ambientes indesejáveis ou em situação de risco leva as pessoas ao "estresse ambiental", segundo Günther et al. (2011). Esses autores apontam que animais sob estresse ficam mais vulneráveis a infecções causadas por agentes patogênicos, ocorrendo, até mesmo, a ampliação para efeitos psicológicos, envolvendo as escalas genéticas e emocionais. A partir de então, o conceito de estresse ambiental passa a ser entendido como "um conjunto de reações que têm por finalidade possibilitar o enfrentamento de situações do ambiente cujos efeitos são negativos e que podem repercutir nas diferentes esferas da pessoa, dependendo, entre outras coisas, de sua capacidade adaptativa". Com isso, passa-se a entender que o bem-estar físico e psicológico das pessoas é influenciado por elementos ambientais como: luz, cor, som, aroma, textura e espaço. Por conseguinte, há uma relação entre estresse e saúde, em que estressores ambientais, como ruídos de trânsito, poluição atmosférica e aglomeração, podem influenciar o estado físico e psicológico do ser humano (GÜNTHER et al., 2011).

Pode-se também tentar entender as relações entre questões que ocorrem no meio ambiente e seus reflexos na sociedade, assim como os efeitos desta naquele, através de trabalhos como o de Günter (2011,), que se refere ao conceito de affordance, utilizado pelos estudos de percepção visual, que trata dos "múltiplos estímulos oferecidos pelo ambiente ao organismo que com ele interage", ou seja, como o ambiente impacta o comportamento e como este é impactado pelo ambiente, havendo uma relação recíproca entre eles. Segundo este conceito, estímulos ambientais provocam e influenciam o comportamento do indivíduo. Para o autor, de acordo com a teoria do campo, as pessoas se encontram num campo de forças, e estas são atraídas ou repelidas "pelos objetos presentes em seu espaço vital", e o que "importa não são as características físicas dos objetos, mas as possibilidades funcionais dos mesmos' (GÜNTER, 2011). Segundo esta teoria, os objetos ou ambiente em si podem ter valência positiva quando atraem a atenção e valência negativa quando repelem a atenção de um indivíduo. A teoria do campo e o termo "valência" foram desenvolvidos por Kurt Lewin (1975), e o termo "affordance" foi cunhado e desenvolvido por Gibson (1986), citado por Günter (2011). Enquanto valência supõe uma influência do ambiente que é percebido e o perceptor, affordance situa-se entre o objeto e perceptor e é bidirecional.

Para Lewin (1975), todo objeto ou evento possui uma valência, que é a capacidade de objetos ou eventos de atrair a atenção ou repulsa de um observador. Tal ação é estimulada por uma necessidade ou uma atividade semiterminada. O interesse é que é experimentado como atração ou repulsa. Ou seja, "a valência de um objeto deriva, usualmente, do fato do objeto ser um meio para a satisfação de uma necessidade" (LEWIN, 1975). Segundo este autor, a percepção de um objeto ou evento segue algumas etapas e começa a partir de um objeto ou evento, que gera um sistema psíquico tenso, produz uma intenção ou desperta um desejo, caracterizado por um estado de atração ou repulsa. Depois, o estado de tensão pode 
remontar um propósito, uma necessidade ou uma atividade semiterminada. Este interesse é que é experimentado como atração ou repulsa. A partir de então, o particular sistema tenso obtém o controle, sobretudo das áreas motoras. Desta forma, diz-se que tais objetos têm uma valência. As "valências dessa espécie operam, ao mesmo tempo (como acontece em algumas outras experiências), como forças de campo, no sentido de que elas dirigem os processos psíquicos, sobretudo as áreas motoras" (LEWIN, 1975). A tensão supracitada precisa ser liberada, ou seja, reduzida, para que o sistema chegue a um equilíbrio. Isto se dá em "certas atividades, causadas em parte por valências e levam a processos de saciação ou à realização de intenções" (LEWIN, 1975).

As valências que objetos possuem em potencial se dão pelo campo de percepção do indivíduo que se amplia, na medida em que ele amadurece. Esse campo de forças influencia no comportamento e varia de indivíduo para indivíduo e de situações ou circunstâncias de momento. Esta força é dada pela direção, intensidade ou potência e por ponto de aplicação ou meta. O campo de força depende também da posição desta em relação ao indivíduo e de outras valências relacionadas ao ambiente.

Pelo que se viu, o ambiente influencia diretamente a vida e comportamento dos indivíduos. Portanto, pode-se estabelecer uma relação entre ambiente e qualidade de vida no tocante aos problemas gerados pelos resíduos. Nesse sentido, Serqueira et al. (2008) afirmam que

Os problemas relacionados aos resíduos sólidos têm se avolumado nas sociedades contemporâneas, implicando a deterioração da qualidade de vida nos grandes centros urbanos. A degradação do meio ambiente natural não pode ser desvinculada de um contexto que inclui comprometimentos da saúde física, transtornos psicológicos e psiquiátricos, e desintegração social. Assim, patologias como doenças infecciosas, degenerativas, cardiovasculares, crises de ansiedade e depressão, síndrome do pânico, dependência química e exacerbação da violência, dentre outras, são os componentes constitucionais de um mesmo fenômeno.

Corroborando, Carvalho et al. (2011) defendem que não há neutralidade dos contextos ambientais sobre o comportamento, saúde e bem-estar dos homens. Citam ainda que "inclusive o ambiente cotidiano e habitual influencia e é influenciado pelo modo como as pessoas percebem, sentem e se comportam naquele contexto ambiental específico", de forma consciente ou inconsciente. Esta recíproca pode levar ao que Fedrizzi (2011) refere como o desenvolvimento da biofilia e biofobia. A biofilia diz respeito às respostas positivas em relação à natureza, enquanto a biofobia, ao contrário, à predisposição individual, associada a bases de informações negativas ou exposição a situações indesejáveis, pois retém o medo e evita estímulos naturais, traduz uma noção de perigo e está ligada a comportamentos ancestrais que procuravam assegurar a sobrevivência. Neste caso, o indivíduo desenvolve medo e/ou aversões a determinados componentes da natureza, como aos animais peçonhentos.

Esses aportes teóricos relacionados à psicologia ambiental são essenciais para o desenvolvimento do conceito de Microcampos de Deterioração Psico-socioambiental - MDPS apresentado à frente. A seguir, apresentam-se os procedimentos metodológicos que permitiram a investigação empírica. O presente estudo estabeleceu como procedimentos metodológicos a escolha lotes vagos, também denominados terrenos baldios ou vazadouros a céu aberto, em interstícios urbanos, na cidade de Fazenda Rio Grande/PR, RMC, 
Brasil, e aplicação de questionário, cuja pesquisa de campo se deu entre os anos de 2012 e 2013.

A escolha dos lotes deu-se a partir da visita in loco a todas ruas e bairros da cidade, observando-se a presença de lotes com deposição massiva de resíduos sólidos domésticos, sendo um dos critérios de escolha. Além disso, os lotes deveriam estar circunscritos à área urbana, a uma distância mínima de 100 metros de áreas marginais, áreas florestadas, alagadas e margens de rios. O objetivo desses critérios foi evitar a contribuição dessas áreas para a presença de vetores nas residências estudadas. $O$ total de lotes encontrados, seguindo esses critérios, foram de 15.

Utilizou-se, com o instrumento de pesquisa, questionário com perguntas estruturadas, solicitando ao entrevistado dados que o caracterizassem socioeconomicamente e identificassem quais vetores (ratos, baratas, moscas, mosquitos, lesmas, animais de ruas) e outros fatores eram comuns na residência, assim como para animais domésticos (cachorros, gatos e outros) e odores desagradáveis. Procedeu-se da mesma forma para a frequência de ocorrências destes parâmetros avaliados. No mesmo sentido, solicitou-se ao entrevistado que registrasse as doenças repetitivas e com diagnóstico médico mais comuns a um ou mais membros da família. As doenças estabelecidas previamente no questionário foram: gripe, cefaleia, infecções, inflamações, manchas na pele, diarreias, problemas respiratórios, problemas cardíacos, dengue, ansiedade, angústia, irritação, depressão e a opção de citar outras (em aberto).

As residências onde foram realizadas as entrevistas obedeceram a três ordens de distâncias em relação ao terreno com resíduos: residências consideradas no entorno imediato ao foco de resíduos (até 25 metros); residências consideradas a média distância (entre 26 e 50 metros) e residências consideradas a longa distância (entre 50 e 100 metros). Para cada intervalo de distância estabelecido, entrevistaram-se 44 pessoas (aquelas que concederam a entrevista), que moravam há um ano ou mais no local, com idade acima de dezoito anos. No total, foram entrevistadas 132 pessoas.

Utilizou-se, para analisar a influência dos terrenos baldios na presença de vetores/odores desagradáveis e de doenças recorrentes nas famílias residentes, segundo a distância do foco, o teste de Correlação de Postos de Spearman (MORETTIN et al., 2002), que mede a associação entre duas variáveis no mínimo ordinais. Este teste é não paramétrico e não exige suposições sobre a distribuição dos dados. A medida chamada 'rho' é um valor que varia de -1 até 1 , em que 1 indica correlação perfeita positiva (se a ordem de uma variável cresce, a outra tende a crescer também) e -1 indica correlação perfeita negativa, se a ordem de uma variável cresce, a outra tende a decrescer). O valor zero indica nenhuma relação entre as variáveis. O p-valor apresentado corresponde ao teste de hipótese que indica se a correlação é estatisticamente diferente de zero. Os testes foram feitos tanto para presença e frequência dos vetores, como para o relato de caso doenças recorrentes a um ou mais membros da família, residentes no local.

Recorreu-se, também, a estudos revisionais e outras literaturas nacionais e internacionais, no sentido de verificar a correlação entre doenças físicas e mentais, relacionadas ao fato de populações residirem nas proximidades de depósitos de resíduos, em especial, aqueles dispostos em vazadouros a céu aberto. Somado a isso, procuram-se recursos teóricos na literatura da psicologia ambiental, como suporte à explicação dos 
fenômenos observados.

\section{RESULTADO E DISCUSSÃO}

\section{Perfil do entrevistado}

Pelos dados analisados das respostas ao questionário, o número médio de anos de estudo dos entrevistados foi de 8,2 anos; o estado civil dos entrevistados é assim distribuído, com seus respectivos percentuais: casados, 65 , $9 \%$; solteiro $20,5 \%$; divorciado, 3,8\%, viúvo, $9,1 \%$, e outro, $0,8 \%$; origem, $75,76 \%$ nasceram no entorno de FRG, ou seja, na zona rural ou cidades da RMC, 22,73\% nasceram em outras áreas rurais/cidades do Estado do Paraná e demais estados do país, e somente 1,52\% nasceram e vivem em FRG; $40,2 \%$ dos entrevistados eram donas de casa, e $24 \%$ homens que trabalhavam à noite e permaneciam em casa durante o dia, os demais respondentes eram filhos acima de 18 anos que permaneciam em casa; a renda média das famílias era de 3,26 salários mínimos; número médio de pessoas residentes de 3,4 pessoas, e 1,7 pessoas, em média, trabalhavam. Questionados se gostavam de morar em FRG, 85,6\% disseram que sim, $7,6 \%$ mais ou menos, e $6,8 \%$ disseram que não gostavam, e os motivos pelos quais foram residir na cidade foram: compra de casa e ou terrenos, 38,6\%; trabalho, 15,2\%; família, 19,7\%; pelo menos dois dos motivos, $3,8 \%$, outros, $14,4 \%$, e não souberam dizer, $8,3 \%$.

\section{Vetores e doenças}

Os testes estatísticos ao nível de 5\% de significância ( $p$-valor abaixo de 0,05 ) demonstraram que, para a presença e frequência (Quadros 1 e 2) de moscas, baratas, ratos, animais de rua e odores desagradáveis, houve significância, ou seja, a presença dos monturos (resíduos) está de fato influenciando a presença contínua desses vetores e odores nas residências. Quanto aos mosquitos, mesmo não obtendo significância, verificou-se uma queda no relato de sua presença, variando, em termos de ocorrência de presença, de 38 a 31 , na medida em que se afastava do foco. Contudo, os outros vetores e a presença de odores são elementos que estão diretamente conectados à presença dos resíduos, funcionando este como um catalisador para procriação e desenvolvimento dos mesmos.

Quadro 1: Resultado do teste do q-simulado, para verificar o grau de significância ao nível de 5\% de probabilidade da correlação entre distância da residência e a presença de vetores e odores desagradáveis. Fazenda Rio Grande/PR.

\begin{tabular}{|l|l|l|}
\hline Moscas & Não & Sim \\
\hline Entorno & 6 & 38 \\
\hline Média & 7 & 37 \\
\hline Longa & 21 & 23 \\
\hline$\%$ & 25,76 & 74,24 \\
\hline p-valor: 0,0002000526*
\end{tabular}

\begin{tabular}{|l|l|l|}
\hline Mosquitos & Não & Sim \\
\hline & 6 & 38 \\
\hline Entorno & 8 & 36 \\
\hline Média & 13 & 31 \\
\hline Longa & 20,45 & 79,55 \\
\hline$\%$ & \multicolumn{2}{|l}{} \\
\hline p-valor: 0,06512727
\end{tabular}

\begin{tabular}{|l|l|l|}
\hline Baratas & Não & Sim \\
\hline & 25 & 19 \\
\hline Entorno & 26 & 18 \\
\hline Média & 35 & 9 \\
\hline Longa & 65,15 & 34,85 \\
\hline$\%$ &
\end{tabular}

\begin{tabular}{|c|c|c|}
\hline \multicolumn{3}{|l|}{ Ratos } \\
\hline & Não & Sim \\
\hline Entorno & 12 & 32 \\
\hline Média & 21 & 23 \\
\hline Longa & 28 & 16 \\
\hline$\%$ & 46,21 & 53,79 \\
\hline
\end{tabular}




\begin{tabular}{|l|l|l|}
\hline p-valor: 0,02526142* & \\
\hline Lesmas & Não & \\
\hline & 12 & Sim \\
\hline Entorno & 19 & 32 \\
\hline Média & 19 & 25 \\
\hline Longa & 37,88 & 25 \\
\hline$\%$ & Não & 62,12 \\
\hline p-valor: 0,125878 & 20 & \\
\hline Odores desagradáveis & Sim \\
\hline \multicolumn{2}{|l}{} \\
\hline Entorno & 26 & 24 \\
\hline Média & 36 & 18 \\
\hline Longa & 62,12 & 87,88 \\
\hline$\%$ & \multicolumn{2}{|l}{} \\
\hline p-valor: $0,0003587956 *$ & \\
\hline
\end{tabular}

\begin{tabular}{|l|l|l|}
\hline p-valor: 0,0005253188* \\
\hline Animais de rua & Não & Sim \\
\hline & 2 & 42 \\
\hline Entorno & 9 & 35 \\
\hline Média & 12 & 32 \\
\hline Longa & 17,42 & 82,58 \\
\hline \% & \multicolumn{2}{|l}{} \\
\hline p-valor: $\mathbf{0 , 0 0 4 7 0 3 6 2 9 *}$ & Sim \\
\hline Outros & Não & 2 \\
\hline & 42 & 1 \\
\hline Entorno & 43 & 0 \\
\hline Média & 44 & 2,27 \\
\hline Longa & 97,73 & \\
\hline \% &
\end{tabular}

Quadro 2: Resultado do teste de correlação de postos de Spearman, para verificar o grau de significância da distribuição de dados entre distância da residência e a frequência de vetores e odores desagradáveis. Fazenda Rio Grande/PR.

\begin{tabular}{|c|c|c|c|c|}
\hline \multicolumn{5}{|c|}{ Quadro de análises } \\
\hline \multicolumn{5}{|c|}{ Teste: Teste de correlação de postos de Spearman } \\
\hline \multicolumn{5}{|l|}{ Moscas } \\
\hline & Não ocorre & Raramente & Ocasion. & Freq. \\
\hline Entorno & 6 & 3 & 18 & 17 \\
\hline Média & 7 & 4 & 17 & 16 \\
\hline Longa & 21 & 1 & 18 & 4 \\
\hline$\%$ & 25,76 & 6,06 & 40,15 & 28,03 \\
\hline
\end{tabular}

\begin{tabular}{|l|l|l|l|l|}
\hline Mosquitos & Não ocorre & Raramente & Ocasion. & Freq. \\
\hline & 6 & 2 & 20 & 16 \\
\hline Entorno & 8 & 3 & 20 & 13 \\
\hline Média & 13 & 2 & 25 & 4 \\
\hline Longa & 20,45 & 5,30 & 49,24 & 25,00 \\
\hline$\%$ & p-valor: 0,003510431* & \\
\hline
\end{tabular}

\begin{tabular}{|l|l|l|l|l|}
\hline Ratos & Não ocorre & Raramente & Ocasion. & Freq. \\
\hline & 11 & 6 & 7 & 20 \\
\hline Entorno & 21 & 6 & 12 & 5 \\
\hline Média & 28 & 4 & 7 & 5 \\
\hline Longa & 45,45 & 12,12 & 19,70 & 22,73 \\
\hline$\%$ & p-valor: 2.57931e-05* & \\
\hline
\end{tabular}

Rho

Rho:

$-0,3335$

Rho:

$-0,2523$

Rho:

$-0,3575$

\begin{tabular}{|l|l|l|l|l|}
\hline Lesmas & Não ocorre & Raramente & Ocasion. & Freq. \\
\hline & 9 & 4 & 9 & 22 \\
\hline Entorno & 19 & 5 & 15 & 5 \\
\hline Média & 19 & 4 & 13 & 8 \\
\hline Longa & 35,61 & 9,85 & 28,03 & 26,52 \\
\hline$\%$ & p-valor: 0,001848538* & \multicolumn{2}{l|}{} \\
\hline
\end{tabular}

Animais de rua

\begin{tabular}{|l|l|l|l|l|}
\hline & Não ocorre & Raramente & Ocasion. & Freq. \\
\hline Entorno & 3 & 2 & 1 & 38 \\
\hline Média & 8 & 4 & 2 & 30 \\
\hline Longa & 12 & 0 & 4 & 28 \\
\hline$\%$ & 17,42 & 4,55 & 5,30 & 72,73 \\
\hline p-valor: $0,01309538 *$
\end{tabular}

Rho:

$-0,2155$

\section{Odores desagradáveis}




\begin{tabular}{|l|l|l|l|l|}
\hline & Não ocorre & Raramente & Ocasion. & Freq. \\
\hline Entorno & 20 & 5 & 10 & 9 \\
\hline Média & 27 & 3 & 9 & 5 \\
\hline Longa & 37 & 2 & 4 & 1 \\
\hline$\%$ & 63,64 & 7,58 & 17,42 & 11,36 \\
\hline p-valor: 8.325363e-05*
\end{tabular}

\begin{tabular}{|l|l|l|l|l|}
\hline Outros & Não ocorre & Raramente & Ocasion. & Freq. \\
\hline & 42 & 0 & 2 & 0 \\
\hline Entorno & 43 & 0 & 0 & 1 \\
\hline Média & 44 & 0 & 0 & 0 \\
\hline Longa & 97,73 & 0,00 & 1,52 & 0,76 \\
\hline$\%$ & p-valor: 0.1580809 & \multicolumn{1}{l|}{} \\
\hline
\end{tabular}

Quanto à ocorrência de doenças comuns e recorrentes às famílias (Quadro 3), tomando como referência a proximidade de residências em relação aos monturos de resíduos, verificou-se queda no número de ocorrências de todas as doenças questionadas, porém aquelas que apresentaram uma relação de significância em nível de $5 \%$ ( $p$-valor menor que 0,05 ) correspondem às infecções, diarreias, inflamações, problemas respiratórios, ansiedade e depressão.

De acordo com o levantamento realizado, existe a contaminação de pessoas que entram em contato ou residem próximas a locais onde se depositam resíduos. As doenças adquiridas advêm tanto do contato direto como pela transmissão por vetores. Constatou-se, neste trabalho, a influência dos vazadouros a céu aberto ocupados com resíduos na presença e frequência de vetores dentro das residências, em função da proximidade ou afastamento do citado foco, inclusive a ocorrência de doenças tradicionalmente transmitidas por vetores, como infecções, diarreias, inflamações e problemas respiratórios. Destaca-se a correlação encontrada para as doenças de caráter mental, como a ansiedade e a depressão. Estas duas últimas são relatadas como tendo correlação entre elas e proximidade e/ou contato com resíduos nos trabalhos de Nakayama et al. (2006); Thompson et al. (2008); Crowley et al. (2003); Geschwind et al. (2010); Serqueira et al. (2008) e Makhubele et al. (2019).

Os trabalhos supracitados foram estudos quase sempre relacionados a áreas que fazem tratamento industrial de resíduos ou de grupos de pessoas, como os catadores de resíduos, que estão em contato direto com os resíduos, como os catadores de lixo. Naqueles trabalhos, apesar de encontrarem relações diretas entre esses empreendimentos e doenças mentais, os estudos não são conclusivos e deixam dúvidas, conforme já citado.

Quadro 3: Resultado do teste do q-simulado, para verificar o grau de significância no nível de $5 \%$ de probabilidade da correlação entre distância da residência e ocorrência de doenças. Fazenda Rio Grande/PR.

\begin{tabular}{|c|c|c|c|c|c|}
\hline \multicolumn{3}{|c|}{ Apresentaram diferenças significantes } & \multicolumn{3}{|c|}{ Não apresentaram diferenças significantes } \\
\hline \multicolumn{3}{|l|}{ Gripe } & \multicolumn{3}{|l|}{ Infecções } \\
\hline & Não & Sim & & Não & Sim \\
\hline Entorno & 15 & 29 & Entorno & 27 & 17 \\
\hline Média & 15 & 29 & Média & 32 & 12 \\
\hline Longa & 20 & 24 & Longa & 39 & 5 \\
\hline$\%$ & 37,88 & 62,12 & $\%$ & 74,24 & 25,76 \\
\hline \multicolumn{3}{|c|}{ p-valor: 0,4937531 } & \multicolumn{3}{|c|}{ p-valor: $0,01549225^{*}$} \\
\hline \multicolumn{3}{|l|}{ Angústia } & \multicolumn{3}{|c|}{ Ansiedade } \\
\hline
\end{tabular}




\begin{tabular}{|l|l|l|}
\hline & Não & Sim \\
\hline Entorno & 25 & 19 \\
\hline Média & 25 & 19 \\
\hline Longa & 29 & 15 \\
\hline$\%$ & 59,85 & 40,15 \\
\hline p-valor: 0,6156922 & \\
\hline
\end{tabular}

\begin{tabular}{|l|l|l|}
\hline & Não & Sim \\
\hline Entorno & 7 & 37 \\
\hline Média & 15 & 29 \\
\hline Longa & 21 & 23 \\
\hline$\%$ & 32,58 & 67,42 \\
\hline p-valor: $\mathbf{0 , 0 0 6 4 9 6 7 5 2}^{*}$ & \\
\hline
\end{tabular}

\begin{tabular}{|c|c|c|}
\hline \multicolumn{3}{|l|}{ Dengue } \\
\hline & Não & Sim \\
\hline Entorno & 43 & 1 \\
\hline Média & 44 & 0 \\
\hline Longa & 44 & 0 \\
\hline$\%$ & 99,24 & 0,76 \\
\hline \multicolumn{3}{|c|}{ p-valor: -não foi possível } \\
\hline \multicolumn{3}{|l|}{ Irritação } \\
\hline & Não & Sim \\
\hline Entorno & 17 & 27 \\
\hline Média & 21 & 23 \\
\hline Longa & 27 & 17 \\
\hline$\%$ & 49,24 & 50,76 \\
\hline \multicolumn{3}{|c|}{ p-valor: 0,1014493 } \\
\hline
\end{tabular}

\begin{tabular}{|c|c|c|}
\hline \multicolumn{3}{|c|}{ Manchas na Pele } \\
\hline & Não & Sim \\
\hline Entorno & 37 & 7 \\
\hline Média & 40 & 4 \\
\hline Longa & 39 & 5 \\
\hline$\%$ & 87,88 & 12,12 \\
\hline \multicolumn{3}{|c|}{ p-valor: 0,7071464 } \\
\hline
\end{tabular}

\begin{tabular}{|c|c|c|}
\hline \multicolumn{3}{|c|}{ Inflamações } \\
\hline & Não & Sim \\
\hline Entorno & 28 & 16 \\
\hline Média & 31 & 13 \\
\hline Longa & 40 & 4 \\
\hline$\%$ & 75 & 25 \\
\hline \multicolumn{3}{|c|}{ p-valor: $0,008995502^{*}$} \\
\hline
\end{tabular}

\begin{tabular}{|l|l|l|}
\hline \multicolumn{2}{|l|}{ Problemas Cardíacos } & Não \\
\hline & 35 & 9 \\
\hline Entorno & 39 & 5 \\
\hline Média & 40 & 4 \\
\hline Longa & 86,36 & 13,64 \\
\hline$\%$ & \multicolumn{2}{|l|}{} \\
\hline p-valor: 0,3533233 &
\end{tabular}

\begin{tabular}{|c|c|c|}
\hline \multicolumn{3}{|c|}{ Depressão } \\
\hline & Não & Sim \\
\hline Entorno & 23 & 21 \\
\hline Média & 34 & 10 \\
\hline Longa & 37 & 7 \\
\hline$\%$ & 71,21 & 28,79 \\
\hline \multicolumn{3}{|c|}{ p-valor: 0,002998501* } \\
\hline \multicolumn{3}{|l|}{ Diarreias } \\
\hline & Não & Sim \\
\hline Entorno & 33 & 11 \\
\hline Média & 32 & 12 \\
\hline Longa & 42 & 2 \\
\hline$\%$ & 81,06 & 18,94 \\
\hline \multicolumn{3}{|c|}{ p-valor: $0,01349325^{*}$} \\
\hline
\end{tabular}

\begin{tabular}{|c|c|c|}
\hline \multicolumn{3}{|l|}{ Outra } \\
\hline & Não & Sim \\
\hline Entorno & 35 & 9 \\
\hline Média & 30 & 14 \\
\hline Longa & 39 & 5 \\
\hline$\%$ & 78,79 & 21,21 \\
\hline \multicolumn{3}{|c|}{ p-valor: 0,06646677 } \\
\hline
\end{tabular}

\begin{tabular}{|c|c|c|}
\hline \multicolumn{3}{|c|}{ Dor de Cabeça } \\
\hline & Não & Sim \\
\hline Entorno & 7 & 37 \\
\hline Média & 11 & 33 \\
\hline Longa & 20 & 24 \\
\hline$\%$ & 28,79 & 71,21 \\
\hline \multicolumn{3}{|c|}{ p-valor: 0,006996502* } \\
\hline \multicolumn{3}{|c|}{ Problemas Respiratórios } \\
\hline & Não & Sim \\
\hline Entorno & 27 & 7 \\
\hline Média & 31 & 3 \\
\hline Longa & 37 & 7 \\
\hline$\%$ & 71,97 & 8,03 \\
\hline
\end{tabular}

Solicitou-se ao entrevistado que relacionasse quais as causas prováveis dos seus respectivos problemas de saúde. Então, 65,1\% do total de 132 entrevistados responderam, e os resultados estão expressos na Figura 1. Vale salientar que muitos elencaram mais de uma resposta. Verificou-se que $19,6 \%$ dos respondentes relacionaram seus problemas de saúde a outras doenças e/ou aquelas mesmas elencadas no questionário da presente pesquisa, e que se tornaram crônicas. As condições de clima da região, onde que predomina o frio, foram relacionadas por $15,2 \%$, seguidas das relações famililiares e perdas por $12,5 \%$, e problemas com saneamento e poluições diversas foram citados por $11,6 \%$. Agregam às demais respostas as questões: financeira, estresse e preocupações diárias, trabalho, entre outras. Dessa forma, na percepção da população, há uma série de fatores causadores dos seus respectivos problemas de saúde, dentre eles, os relacionados às questões de saneamento. 


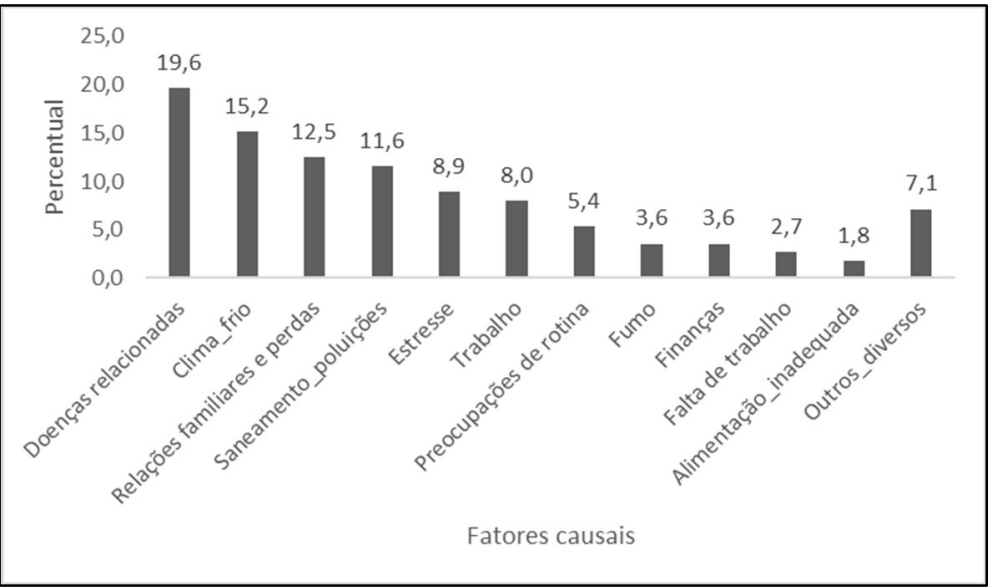

Figura 1: Percepção dos entrevistados sobre as possíveis causas de seus problemas de saúde física e mental. Fazenda Rio Grande/PR.

Essa tentativa de levantar os possíves elementos causais dos problemas de saúde encontrados foi no sentido de tentar perscrutar se poderia haver outros elementos causais, além daqueles relacionados à presença dos resíduos sólidos. Triassi et al. (2015) chamam atenção para a necessidade de coleta de dados mais locailizados e detalhados para esse tipo de trabalho. Nesse sentido, o presente estudo procurou antecipar parte dos possíveis problemas levantados por aqueles autores. Contudo, vale lembrar, segundo Mucelin et al. (2008), que

A vivência cotidiana muitas vezes mascara circunstâncias visíveis, mas não perceptíveis. Mesmo contemplando casos de agressões ao ambiente, os hábitos cotidianos concorrem para que o morador urbano não reflita sobre as consequências de tais hábitos, mesmo quando possui informações a esse respeito. (MUCELIN et al., 2008).

Dessa forma, na rotina do dia a dia, há a possibilidade das pessoas passarem a não mais perceberem a presença dos resíduos sólidos e seus efeitos. Não resta dúvida de que muitos são os fatores que poderão estar influenciando o estado de saúde dos residentes do entorno de 'monturos' de resíduos, porém os dados do presente estudo confluem para que um dos principais causadores dos problemas encontrados esteja relacionado à problemática da deposição dos resíduos nos terrenos baldios.

Durante os trabalhos de campo, observaram-se queimadas constantes em vazadouros a céu aberto com lixo, ou seja, as pessoas queimam os resíduos nos terrenos, quando estes apresentam um volume que acaba incomodando a vizinhança. Esses terrenos com resíduos também funcionam como microincineradores, causando a poluição por gases e liberando diversas susbtâncias relacionadas à consituição dos resíduos ali presentes, que são das mais diversas tipologias (resíduos orgânicos, papel, vidro, metais, madeiras diversas, móveis, colchões, animais mortos, baterias, pilhas, resíduos eletrônicos, remédios, às vezes, presença de alguns tipos de resíduos hospitalares etc.).

Outro aspecto recorrente, relatado pelos entrevistados e obervados durante o mapeamento de campo, é que, nos terrenos com resíduos, ocorre a presença de 'deliquentes' e usuários de droga, que utilizam estes terrenos como abrigo temporário, inclusive para o uso de entorpecentes ou planejar pequenos furtos nas casas do entorno; os terrenos com resíduos também são objeto de conflitos entre vizinhos que jogam lixo e os que não jogam, entre estes e os donos de terrenos que não os limpam. Além dos resíduos 
que naturalmente causam grandes problemas, emergem esses outros de caráter social, além do efeito estético negativo causado pela poluição visual.

Constatou-se, a partir de Rodrigues (1988), a formação de territórios indesejados ou segregados pelo lixo, de modo que, nesses locais de deposição, forma-se um conjunto de situações inaceitáveis do ponto de vista socioambiental. Juntam-se a este fato os conceitos trazidos por Serqueira et al. (2008), Fedrizzi (2011), Günter (2011), Carvalho et al. (2011), que ressaltam que não se pode desvincular a saúde psicofísica do indivíduo de contextos ambientais deteriorados. Na mesma seara, verifica-se, com Lewin (1975), que todo objeto ou evento possui uma valência (positiva ou negativa), que é a capacidade de objetos ou eventos atraírem e repulsarem a atenção de um observador, estimulada por uma necessidade humana ou atividade semiterminada, e isto forma um campo que se amplia à medida que o indivíduo se desenvolve. Desta forma, não há dúvida de que os terrenos com resíduos são grandes focos de problemas socioambientais, proporcionando, assim, a formação do que se pode denominar de Microcampos de Deterioração Psicossocioambiental - MDPS.

Assim, os MDPS são formados a partir de monturos de resíduos dispostos a céu aberto, em terrenos baldios, que são: fonte de presença de vetores; gases tóxicos devido à queima; presença de usuários de drogas e praticantes de pequenos furtos, gerando também conflitos de vizinhança e efeitos de poluição visual. Tal ambiente cria um sentido de insegurança que contribui negativamente para a saúde física e psicológica das pessoas do seu entorno e é dependente da distância, ou seja, há uma distribuição espacial de concentração e dispersão desses elementos. São fatores que, quando agregados, criam um ambiente psicosocioambientalmente deteriorado.

O pressuposto que então se forma é o de que cada um desses MDPS comporta um maior ou menor grau de influência na fixação das causas de problemas de saúde física e psicológica dos indivíduos que vivem nestas imediações, cabendo dimensioná-los e neutralizar seus efeitos. O elemento ambiental contido no conceito do MDPS representa a deterioração ambiental a que o local fica exposto, dados os diversos teores de concentração de elementos tóxicos, material biológico contaminante, odores desagradáveis e poluição visual. O segundo pressuposto surge como complemento do anterior e estabelece que a maior ou menor sujeição aos fatores de deterioração é proporcional à proximidade e ao afastamento entre a MDPS e o foco principal de deposição. A situação encontrada pode ser ilustrada pelo mapa conceitual na Figura 2.

O mapa configura as situações constatadas em campo, onde, à medida que o observador se afastava do terreno contaminado por resíduos, os fatores causadores dos problemas apresentavam tendência à diminuição. Desta forma, há, nesses locais, uma relação inversamente proporcional entre os fatores que tanto podem levar pessoas do entorno a viverem em constante tensão, como podem explicar a correlação positiva entre o local e ansiedade e depressão (problemas de natureza psicológica) - uma relação entre afastamento/diminuição e proximidade/aumento. Com isto, pode-se afirmar que, à medida que o morador reside mais próximo desses locais, há uma deterioração da qualidade de vida, bem como das condições ambientais. 
O escopo da pesquisa foi medir este campo em FRG e extrair dessa medição o mapa conceitual integrando observações em nível micro (pequenas quantidades de lixo, abrangendo área de, no máximo, um lote padrão) aos efeitos daqueles citados na literatura para grandes empreendimentos, como aterros sanitários, lixões, incineradores de grande porte, depósitos de lixo tóxico, os quais podem ser denominados de Macrocampos de Deterioração Psico-socioambiental, destacando-se os efeitos psicológicos. Os termos da pesquisa são complementares e ajudam a caracterizar e justificar a relevância das medições quando se pensa que, a continuar o cenário de cornucópia do lixo, como alerta Waldman (2010), ocorrerá, em nível de planeta, um Hipercampo de Deterioração Psico-socioambiental com os resíduos sólidos, líquidos e gasosos, com suas variáveis tóxicas, radioativas e até mesmo os resíduos espaciais.

Salienta-se, também, que este trabalho eleva, em nível de detalhes e aplicação de metodologia que transpôs alguns obstáculos metodológicos levantados por Triassi et al. (2015), sobre a problemática de se investigar a correlação entre a deposição irregular de resíduos sólidos e a saúde dos residentes do entorno.

O que se defende é que há uma deposição generalizada de resíduos sólidos por toda a cidade de FRG, intensa o bastante para tornar imperioso seu estudo permanente, em especial, a prática do biomonitoramento dos residentes, conforme sugerido por Triassi et al. (2015). O destaque deve ser dado àqueles resíduos dispostos em vazadouros a céu aberto que, na escala das medições pelo princípio afastamento/diminuição e proximidade/aumento, formando os MDPS, fornecem a leitura de em qual intensidade pequenos depósitos estão levando a população a riscos e vulnerabilidades socioambientais contínuos, bem como ao perigo de contrair doenças psicofísicas. Desta forma, viver próximo a um MDPS é viver em situação de riscos e perigos constantes.

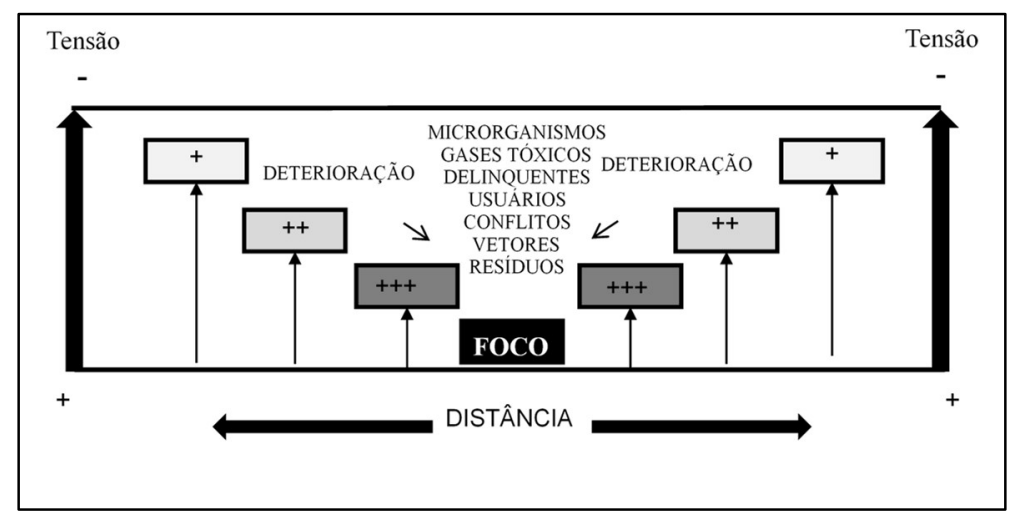

Figura 2: Mapa conceitual que expressa o Microcampo de Deterioração Psico-socioambiental. Fazenda Rio Grande PR. 2013.

Todo este conjunto de problemas torna o lugar insalubre, formando um gradiente de tensão de maior para menor grau. Esta situação leva a concluir que é nos próprios locais que se cria o que acima se descreveu e nomeou como Microcampos de Deterioração Psico-socioambiental. Esta é uma expressão adotada para fazer referência à condição resultante das contradições de uma sociedade que apregoa a garantia de bemestar a todas as pessoas, a partir de um modelo de desenvolvimento que tem como um dos pilares o crescimento econômico. Tal postura se sustenta, no entanto, no consumismo exagerado, na subjugação desta mesma sociedade aos seus cânones e na dilapidação dos bens naturais, agindo de forma organizada e 
coordenada em nível global, por meio de seus articuladores corporativos e agentes financeiros.

\section{CONCLUSÕES}

A geração do Microcampo de Deterioração Psico-socioambiental é estabelecida a partir da constatação, neste trabalho, de que pequenos depósitos de resíduos localizados em vazadouros a céu aberto têm uma relação direta com a presença de vetores nas residências, sendo significativa a presença de ratos, baratas, moscas, animais de rua e também os odores desagradáveis. Também evidencia um conjunto recorrente de problemas de saúde nas residências, como as infecções, inflamações, diarreias, cefaleia, problemas respiratórios, ansiedade e depressão. Ou seja, na medida em que há terrenos contaminados e, quanto mais próximos aos focos de deposição esses terrenos estiverem da residência, maior tende a ser o relato da incidência desses problemas. Somam-se a essa situação as constantes tensões provocadas pelo fato de os vazadouros a céu aberto contaminados funcionarem como abrigo temporário de usuários de drogas e vândalos, bem como de gerarem potenciais conflitos e discórdia entre vizinhos e proprietários. Ações realizadas nesses ambientes denominados Microcampos de Deterioração Psico-socioambiental têm como resultado a produção social abstrata de espaços indesejáveis.

Em Fazenda Rio Grande, a maioria dos terrenos com resíduos são queimados de forma recorrente. Neste sentido, em menor escala, podem estes locais estar de forma lenta e difusa levando as pessoas a apresentarem, não só os problemas de saúde causados por vetores, mas aqueles de natureza mental e psicológica, causados por gases e/ou substâncias tóxicas emitidas nos grandes empreendimentos de tratamento de resíduos, como os depósitos de lixo tóxico, aterros sanitários, lixões e incineradores. Dessa forma, o presente estudo contribui também para diminuir as dúvidas quanto à influência dos grandes empreendimentos de tratamento de resíduos, como causadores de problemas de saúde, tanto física como mental, haja vista que, na pequena escala de terrenos com resíduos, foi observada esta influência. É necessária a continuidade desse tipo de estudo, no sentido de investigar se é um fenômeno isolado, além de aprofundar investigação na questão dos contaminantes biológicos e metais pesados, bem como estudos de biomonitoramento.

\section{REFERÊNCIAS}

BANDARA, N. J. G. J.. Environmental Impacts with Waste Disposal Practices in a Suburban Municipality in Sri Lanka. Journal Environment and Waste Management, v.6, n.1-2, p.107-116, 2010. DOI: http://doi.org/10.1504/IJEWM.2010.033987

BRANDÃO JUNIOR, E. L.; BERNARDO, G. P.; BERNARDO, L. P.; NASCIMENTO, S; I. B.; LIMA, B. F. R.; SILVA, K. V. C. C.; CAVALCANTE, G. M. E.; RULIM, A. L. L. L.; DUARTE, J. O.. Queima inadequada de resíduos sólidos domésticos, principais gases tóxicos e manifestações clínicas: uma revisão de literatura. Rev. Mult. Psic., v.12, n.42, p.602-612, 2018.
CARVALHO, M. I. C.; CAVALCANTE, S.; NÓBREGA, L. M. A.. Ambiente. In: CAVALCANTE, S.; ELALI, G. A.. Temas básicos em psicologia ambiental. Petrópolis: Vozes, 2011. p.28-43

CAVALLET, L. E.; CARVALHO, S. G.; FORTES-NETO, P.. Metais pesados no rejeito e na água em área de descarte de resíduos sólidos urbanos. Revista Ambiente e Água, v.8, n.3, p.229-238, 2013. DOI: http://doi.org/10.4136/1980-993X

CROWLEY, D.; STAINES, A.; COLLINS, C.; BRACKEN, J.; BRUEN, $M$.. Health and Environmental Effects of Landfilling and Incineration of Waste: A Literature Review. Dublin: School of Food Science and Environmental Health, 2003. 
DAMATTA, R.. A Casa e a rua: espaço, cidadania, mulher e morte no Brasil. 5 ed. Rio de Janeiro: Guanabara, 1997.

DORST, J.. Por uma ecologia política: antes que a natureza morra. São Paulo: Edgard Blücher, 1973.

FAZZO, L.; SANTIS, M.; MITIS, F.; BENEDETT, I.; MARTUZZI, M.; COMBA, P.; FUSCO, M.. Ecological Studies of Cancer Incidence in an Area Interested by Dumping Waste Sites in Campania (Italy). Ann Ist Super Sanità, v.47, n.2, p.181-191, 2011. DOI: http://doi.org/10.4415/ANN 110210

FAZZO, L.; MINICHILLI, F.; SANTORO, M.; CECCARINI, A.; SETA, M. D.; BIANCHI, F.; COMBA, P.; MARTUZZI, M.. Hazardous waste and health impact: a systematic review of the scientific literature. Envioromental Health, v.16, n.107, 2017. DOI: http://doi.org/10.1186/s12940-017-0311-8

FEDRIZZI, B.. Biofilia e biofobia. In: CAVALCANTE, S.; ELALI, G. A.. Temas básicos em psicologia ambiental. Petrópolis: Vozes, 2011. p.98-104.

FERREIRA, J. A.; ANJOS, L. A.. Aspectos de Saúde Coletiva e Ocupacional Associados à Gestão dos Resíduos Sólidos Municipais. Cadernos Saúde Pública, v.17 n.3, p.689-696, 2001.

FIGUEIREDO, P. J. M.. A sociedade do lixo: os resíduos a questão energética e a crise ambiental. Piracicaba: UNIMEP, 1994.

GESCHWIND, S. S. A.; STOLWIJK, A. J.; BRACKEN, M.; FITZGERALD, E.; STARK, A.; OLSEN, C.; MELIUS, J.. Risk of Congenital Malformations Associated with Proximity to Hazardous Waste Sites. American Journal of Epidemiology, v.135, n.11, p.1197-1207, 1992. DOI: http://doi.org/10.1093/oxfordjournals.aje.a116226

GÜNTHER, I. A.; FRAGELLI, T. B. O.. Estresse ambiental. In: CAVALCANTE, S.; ELALI, G. A.. Temas básicos em psicologia ambiental. Petrópolis: Vozes, 2011. p.191-207.

HELLER L.. Resíduos sólidos domésticos e saúde: populações vulneráveis e situações de risco. In: PORTO, M. F. S.; FREITAS, C. M.. Problemas ambientais e vulnerabilidade: abordagens integradoras para o campo da saúde pública. Rio de Janeiro: Fiocruz, 2002. p.99-124.

JALIL, A.. Sustainable Development in Malaysia: A case study on household waste management. Journal of Sustainable Development, v.3, n.3, p. 91-102, 2010.

JOSEPH, K.. Solid waste dump sites to sustainable landfills. In: EnviroVision. Centre for Environmental Studies, 2002. p.1-14.

LEWIN, K.. Teoria dinâmica da personalidade. São Paulo: Cultrix, 1975.

LIMA, J. D.. Gestão de resíduos sólidos urbanos no Brasil. Campina Grande: ABES, 2001.

MAKHUBELE, M.; RAVHUHALLI, K.; KUONZA, L.; MATHEE, A.; KGALAMONO, S.; MADE, F.; TLOTLENG, N.; KOOTBODIEN, T.; NTLEBI, V.; WILSON, K; NAICKER, N.. Common Mental Health Disorders among Informal Waste Pickers in Johannesburg, South Africa 2018: A Cross-Sectional Study. Int. J. Environ.
Res. Public. Health, v.16, n.2618, 2019. DOI: http://doi.org/10.3390/ijerph16142618

MORAES, L. R. S.. Acondicionamento e Coleta de Resíduos Sólidos Domiciliares e Impactos a Saúde de Crianças Residentes em Assentamentos Periurbanos de Salvador, Bahia, Brasil. Cadernos Saúde Pública, v.23, p.643-649, 2007. DOI: http://doi.org/10.1590/S0102$311 \times 2007001600024$

MORETTIN, P. A.; BUSSAB, W. O.. Estatística básica. 5 ed, São Paulo: Saraiva, 2002.

MUCELIN, C. A.; BELLINI, M.. Lixo e impactos perceptíveis no ecossistema urbano. Sociedade \& Natureza, Uberlândia, v.20, n.1, p.11-124, 2008.

MUDZENGERERE, F. H.; CHIGWENYA, A.. Waste management in Bulawayo city council in Zimbabwe: in search of sustainable waste management in the city. Journal of Sustainable Development in Africa, Pennsylvania, v.14, n.1, p.228-244, 2012.

MUÑOZ, S. I. S.. Impacto ambiental na área do aterro sanitário e incinerador de resíduos sólidos de Ribeirão Preto/SP: avaliação dos níveis de metais pesados. Tese (Doutorado em Enfermagem e Saúde Pública) - Universidade de São Paulo, Ribeirão Preto, 2002.

NAKAYAMA, O.; OHKUMA, K.. Mental Health Status of Municipal Solid Waste Incinerator Workers Compared with Local Government Office Workers. Industrial Health, v.44, p.613-618, 2006. DOI: http://doi.org/10.2486/indhealth.44.613

NUNESMAIA, M. F.. A Gestão dos Resíduos Sólidos e suas Limitações. Revista Baiana de Tecnologia, v.17, n.1, p.120129, 2002.

OLIVEIRA, B. O. S.; TUCCI, C. A. F.; NEVES-JÚNIOR, A. F.; SANTOS, A. A.. Avaliação dos solos e das águas nas áreas de influência de disposição de resíduos sólidos urbanos de Humaitá, Amazonas. Engenharia Sanitária Ambiental, v.21 n.3, p.593-601, 2016. DOI: http://doi.org/10.1590/S1413$\underline{41522016133274}$

ORSI, R. A.. Convivendo com O Lixo: a vulnerabilidade socioambiental no bairro Jardim Graminha, Leme. In: CONGRESSO DE MEDIO AMBIENTE, 7. Anais. La Plata: AUGM, 2002. p.1-20.

REYES, J. A. M.. El problema de la basura en la Ciudad de México. Adolfo Christlieb Ibarrola. Fundaçión de Estudi8os Urbaonos y Metroplitanos, 2004.

RODRIGUES, A. M.. Produção e consumo do e no espaço: Problemática ambiental urbana. São Paulo: Hucitec, 1998.

SANTOS, M. C. L.; DIAS, S. L. F. G.. Resíduos sólidos urbanos e seus impactos socioambientais. São Paulo: USP, 2012.

SEDU. Secretaria Especial de Desenvolvimento Urbano da Presidência da República. Gestão integrada de resíduos sólidos: Manual Gerenciamento Integrado de Resíduos Sólidos. Rio de Janeiro: IBAM, 2001. 
SEQUEIRA, M. M.; MORAES, M. S.. Saúde coletiva, resíduos sólidos urbanos e os catadores de lixo. Ciência \& Saúde Coletiva, Rio de Janeiro, v.14 n. 6, p.2115-2122, 2008. DOI: http://doi.org/10.1590/S1413-81232009000600018

THOMPSON, J.; ANTHONY, H.. The health effects of waste incinerators: 4th Report of the British Society for Ecological Medicine. 2 ed. 2008.

TORO, A. A. L.; ROMERO, J. C. R.; CEBADOR, M. S.; JIMÉNEZ, $R$. A.. Consideration of stakeholder interests in the planning of sustainable waste management programmers. Waste Management e Research, v.34, n.10, 2016. DOI: http://doi.org/10.1177/0734242X16657606

TRIASSI, M.; ALFANO, R.; ILLARIO, M.; NARDOE, A.; CAPRALE, O.; MONTUORI, P.. Environmental Pollution from Illegal Waste Disposal and Health Effects: A Review on the 'Triangle of Death'. Int. J. Environ. Res. Public. Health, v.12, p.12161236, 2015. DOI: http://doi.org/10.3390/ijerph120201216
UNEP. United Nations Environment Programme. Solid waste management. Meeting Development Goals in Small Urban Centers: Water and Sanitation in the World Cities. London: Earthscan Publications, 2006.

VELOSO, V. P.. Os restos na história: percepções sobre resíduos. Ciência \& Saúde Coletiva, v.6, n.13, p.1953-1964, 2008. DOI: http://doi.org/10.1590/S141381232008000600031

VEYRET, Y.. Os riscos: o homem como agressor e vítima do meio ambiente. São Paulo: Contexto, 2007.

WALDMAN, M.. Lixo: cenários e desafios. São Paulo: Cortez, 2010.

WOLFF, D. B.; GONÇALVES, I. H.; GASTALDINI, M. C. C.; SOUZA, M. M.. Resíduos sólidos em um sistema de drenagem urbana no município de Santa Maria (RS). Engenharia Sanitária Ambiental, v.21, n.1, p.151-158, 2016. DOI: http://doi.org/10.1590/S1413-41520201600100132089

A CBPC - Companhia Brasileira de Produção Científica (CNPJ: 11.221.422/0001-03) detém os direitos materiais desta publicação. Os direitos referem-se à publicação do trabalho em qualquer parte do mundo, incluindo os direitos às renovações, expansões e disseminações da contribuição, bem como outros direitos subsidiários. Todos os trabalhos publicados eletronicamente poderão posteriormente ser publicados em coletâneas impressas sob coordenação da Sustenere Publishing, da Companhia Brasileira de Produção Científica e seus parceiros autorizados. Os (as) autores (as) preservam os direitos autorais, mas não têm permissão para a publicação da contribuição em outro meio, impresso ou digital, em português ou em tradução. 